\title{
JOHN DEWEY'S THEORY OF INQUIRY. QUANTUM PHYSICS, ECOLOGY AND THE MYTH OF THE SCIENTIFIC METHOD
}

\author{
Joaquín Fernández Mateo \\ bttps://orcid.org/0000-0002-9560-5197 \\ Universidad Rey Juan Carlos, Madrid \\ https://doi.org/10.15304/ag.40.1.6659
}

\section{Resumen}

La moderna filosofía de la ciencia no ha logrado definir de forma concluyente en qué consiste el método científico. Por el contrario, la práctica científica parece consistir en un pluralismo metodológico, definición que conecta con fragmentos esenciales de la obra de John Dewey, Lógica, Teoría de la Investigación. Para Dewey, incluso las formas de la lógica emergen de los problemas definidos en las situaciones indeterminadas. Un ejemplo histórico fue la introducción de la noción de complementariedad en física, que permitió la interpretación de forma coherente de dos experimentos paradójicos que generaban confusión. El pensamiento de Dewey demuestra su actualidad al ayudarnos a definir el patrón de la investigación. El pluralismo metodológico y la dependencia de la lógica de los problemas de investigación no es algo que vaya a suceder, es algo que ha sucedido y sucede efectivamente en las prácticas científicas.

Palabras clave: pragmatismo, método científico, Dewey, epistemología, filosofía de la ciencia, mecánica cuántica.

\begin{abstract}
The modern philosophy of science has not succeeded in defining conclusively what the scientific method consists in. On the contrary, scientific practice seems to consist in a
\end{abstract}

Recibido: 06/03/2020. Aceptado: 30/06/2020. 
methodological pluralism, a definition that connects with essential fragments of John Dewey's Logic, the Theory of Inquiry. For Dewey, even the forms of logic emerge from the problems defined in indeterminate situations. A historical example was the introduction of the notion of complementarity in physics, which allowed the interpretation of two confusingly paradoxical experiments in a coherent way. Dewey's thought demonstrates its relevance by helping us to define the pattern of inquiry. Methodological pluralism and the dependence of logic on research problems is not something that will happen, it is something that has happened and does happen in scientific practices.

Keywords: pragmatism, scientific method, Dewey, epistemology, philosophy of science, quantum mechanics.

\section{Introduction}

The philosophy of modern science has not succeeded in conclusively defining what the scientific method consists in (Rorty, 1982; Valor, 2006; Rivadulla, 2015). The belief in a science as a system of true propositions regarding the world - the positivist project of the Vienna Circle- was questioned by Karl Popper's critical realism by introducing uncertainty into the program of a sure science. The falsificationist criterion of scientific demarcation was eroded by the works of Thomas Kuhn, Imre Lakatos, and Paul Feyerabend: "Popper has failed to solve his fundamental problem-the problem of demarcation" (Maxwell, 1972, p. 137). Currently, the philosophy of science has been generating new tendencies stemming from the ideas of Charles Pierce, William James, and John Dewey (Valor, 2011; Rivadulla, 2015). A clear example of this is found in the debate between realism and instrumentalism, a philosophical debate that has been transferred to the interior of physics, affecting the foundations of quantum mechanics. At the present time, different approximations combine quantum mechanics with pragmatism. For Healey (2018, p. 132), "quantum theory introduces terms like 'quantum state' and 'quantum field' that they are not intended to mirror the physical world but to guide scientists and other situated agents in better deploying representational resources they already have or are engaged in developing". For Bächtold (2008, p. 243), all terms of quantum mechanics can be interpreted in the light of physicist practice, "this means, there is no need to connect these terms and mathematical components to elements (or features) assumed to belong (resp. to characterize) the world as it is in itself".

In this philosophical and scientific context, this article sets out the following objectives. In the first place, to subject to criticism the insufficiencies of the modern philosophy of science when it comes to defining what said 
method consists in. Secondly, to generate a more adequate description of the real functioning of scientific activity based on Dewey's approaches in his Logic, Theory of Inquiry. As a consequence of these approaches, a methodological pluralism and a new conception of logic emerges. Consequently, the final aim of this article is to explore a philosophical approach that would stimulate the development of knowledge without the limitations of epistemological dualism and methodological monism.

Pragmatism is a way of thinking that tries to overcome the dualisms that have occurred in modern philosophy, in general, and in the philosophy of science, in particular. Said dualisms have created insurmountable divisions by radically separating different pairs of concepts; the activity of the mind opposed to the passivity of matter; the theoretical capacity of thought is faced against the practical and self-interested character of action (Faerna, 1996). Pragmatist thought tries to integrate the concepts excluded by the representative vision of knowledge. For Dewey (1938, p. 79), "the basic problem of present culture and associated living is that of effecting integration where division". As a result of this division, the notion of situation has an integrative function. For Dewey, the situation is a contextual whole, a system of interactions between organism and environment with physical, biological and cultural aspects. These approaches are not unconnected to the philosophical postulates of physicists and scientists, as the similitude with the monist metaphysics of the theoretical physicist Erwin Schrödinger demonstrates.

This paper takes as its starting point the theory of inquiry developed by John Dewey in Logic, the Theory of Inquiry. Unlike positivist thought, verification will not be the methodological criteria of validation of scientific thought, rather experimentation. In Dewey's thought, the theories are not going to be validated by observation or by the correspondence with reality-understood as an object in and of itself-rather by its capacity to resolve the problems that occur given the conditions that initiate the scientific inquiry, the conditions of uncertainty: "inquiry is the controlled or directed transformation of an indeterminate situation into one that is so determinate in its constituent distinctions and relations as to convert the elements of the original situation into a unified whole" (Dewey, 1938, p. 104-105). For Dewey, inquiry is always a transformative process: "all controlled inquiry and all institution of grounded assertion necessarily contains a practical factor; an activity of doing and making which reshapes antecedent existential material which sets the problem of inquiry" (1938, p. 160). 
Logical positivism and analytical philosophy, in their quest for meaning, generated discourses that tried to define the method of science in order to establish criteria of demarcation between scientific activities and nonscientific activities. The scientific method, defined as verification method-according to the positivism of the Vienna Circle-or as a falsification method-according to Popper's critical realism-appeared as the criteria to separate scientific knowledge from other kinds of activities. The scientific method was defined as an obligatory procedure, a set of necessary rules that had to be followed in order to reach certain, objective knowledge. The success of physical science justified its application to the rest of the scientific areas, such as the social sciences. Yet, the definition of scientific method has been a philosophical problem of great magnitude. Though the success in the prediction of natural phenomena is unquestionable, it is not so clear that the key to that success lies in the utilization of a specific method. Although that method has been utilized to distinguish between scientific knowledge and nonscientific knowledge, it is not clear what said method consists in. For that, the question of method has come to be a philosophical problem of the first order and is currently the subject of discussion:

In this sense, 'method' and 'rationality' are names for suitable balance between respect for the opinions of one's fellows and respect for the stubbornness of sensation. But epistemologically-centered philosophy has wanted notions of 'method' and 'rationality' which signify more than good epistemic manners, notions which describe the way in which the mind is naturally fitted to learn Nature Own's Language (Rorty, 1982, p. 195).

\section{The epistemological foundations of modernity}

The project of modernity relies on the primary qualities, as opposed to the subjective qualities, produced by the impact of reality on the mind: “Galileo's program-to base the description of physical phenomena on measurable quantities - has afforded a solid foundation for the ordering of an ever larger field of experience" (Bohr, 1963: p. 1). The new scientific project restricts the real qualities of the bodies to those that can be understood in mechanical or geometric terms, the rest of the qualities being mere appearances derived from the first ones. In general terms, this project is identified with the works of Locke and Boyle, but different versions of them can be found in Galileo, Hobbes, Descartes, Spinoza, Newton, Leibniz, Hume or Kant (Nolan, 2011). For Burtt (2003, p. 118), Descartes, like Galileo, thinks that "we only know the objects in mathematical terms [...] 
Hence the secondary qualities, when considered as belonging to the objects, like the primary, inevitably appear to his mind obscure and confused". The development of a theory of representation would allow us to connect both worlds previously separated; to polish the mirror of the mind with true representations. To overcome the difficulty of justifying the belief in the existence of a world outside the ideas of the subject, John Locke "provided the background of the theory of representative realism" (Dewey, 1938, p. 526). The primary qualities would correspond to objective reality, while the secondary qualities would not attain the status of real because of its relational nature.

The primary qualities would correspond to the world as it is in itself. This conception of knowledge refers the rest of the representations to scientific uselessness, which explains the inferiority complex of human sciences that do not follow the marked methodological criteria. The privilege of certain formalistic ideas has drawn geometrical lines over human beings (Blum, 1980), non-human animals (Tafalla, 2013) and nature (Puleo, 2017). The epistemology of modernity gave rise to a dualistic moral theory. Sensitive elements were left out of rational thought, at the bottom of the hierarchy. For Marion Young (1987, p. 63), "as a consequence of the opposition between reason and desire, moral decisions grounded in considerations of sympathy, caring and an assessment of differentiated need are defined as not rational, not 'objective', merely sentimental". A complementary reason, which does not confront dimensions in the opposite way-reason versus affectivity or vice versa-would make it possible to recognize elements excluded by an objectivist conception of knowledge that has a psychological and moral impact. For Bohr (1963: p. 7), "the integrity of living organisms and the characteristics of conscious individuals and human cultures present features of wholeness, the account of which implies a typical complementary mode of description".

The relational vision of knowledge favors the development of other forms of knowledge with other principles, such as quantum physics and ecology (Naess, 1985). Relational ideas have scientific utility: "the Galileo type of answer uses a distinction that is useful within limits but breaks down if absolutized" (1985, p. 418). Ecological thinking would try to overcome a reality conceived in dichotomous terms: "there are no completely separable objects" (1985, p. 419). Reality is articulated in a relational field, a network of interrelations that does not establish an epistemological abyss between primary qualities-nature as it would be in itself-and the so-called secondary qualities-nature as it is perceived. These ideas lead us 
to respect the integrity of the totality, a relational field without exclusion of qualities. A relational field would not distinguish between subjective and objective aspects-the beauty of nature versus its consideration as an object of measurement and calculation-but between different aspects of the same unitary reality:

The identification of primary properties with those of objects themselves leads to a conception of nature without any of the qualities we experience spontaneously. Now, there is no good reason why we should not look upon such a bleak nature as just a resource. Every appeal to save parts of nature based on reference to sense-qualities of any kind becomes meaningless. Every passionate appeal that reveals deep feelings, empathy, and even identification with natural phenomena must then be ruled out as irrelevant. The sphere of real facts is narrowed down to that of mechanically interpreted mathematical physics (1985, p. 420).

The Newtonian-Cartesian ontology established a type of external relationship with nature that allowed iniquitous socioeconomic practices both for people and for the planetary ecological balance (Speranza, 2006). The theoretical and epistemological frameworks based on this ontology have proven to be insufficient to solve the problems of a complex reality-solving problems based on calculation and computation without developing an ethic of care and empathy, for example. The use of a new theoretical framework based on a complementary logic, without the use of pairs of opposing concepts could be satisfactory for the problems faced by human societies.

Copenhagen's interpretation of quantum physics offers a relational view of knowledge: there are no completely separable objects. Along with the relations of indetermination, the quantum postulate and Born's statistical interpretation, Bohr's principle of complementarity is one of the cornerstones of the Copenhagen interpretation (Castellá, 2016). The notion of complementarity made it possible to understand the two natures of light in a coherent way. For Bohr $(1958$, p. 40) "evidence obtained under different experimental conditions cannot be comprehended within a single picture, but must be regarded as complementary in the sense that only the totality of the phenomena exhausts the possible information about the objects". The principle of complementarity provided by the Copenhagen interpretation of quantum physics has an application in the human and social sciences. In fact - and this point is a clear convergence of Bohr's and Dewey's thinking-, Bohr had a unitary conception of all sciences, which allowed him to extend the notion of complementarity to psychology or anthropology: "using the word much as it is used, in atomic physics, to characterize the relationship between experiences obtained by different experimental arrangements and 
visualizable only by mutually exclusive ideas, we may truly say that different human cultures are complementary to each other" $(1958$, p. 30).

If we follow John Dewey's Theory of Inquiry, we discover that logic is not a fixed research budget, but that it is developed in the research process itself. For Dewey, "contemporary logic has moved far enough to criticize the old logic form" (Dewey, 1938, p. 91). According to Bohr (1958, p. $5-6)$, "as has often happened in science when new discoveries have led to the recognition of an essential limitation of concepts hitherto considered as indispensable, we are rewarded by getting a wider view". Just as the notion of complementarity made it possible to understand certain experimental physical situations, we hope that a different understanding of how science works allows us a wider vision capable of solving the new problems we face. Faced with the classic opposition between subject and object, a complementary view of our social being would make it possible to understand that the conservation of biodiversity and ecosystems is just as necessary as the purely quantitative aspects in economic terms. This would lead us to recognize, for example, ethical forms that include the value of nature and non-human animals beyond their quantitative reduction (Velasco, 2016).

\section{The crisis of logical positivism and the new pragmatic approaches}

Logical positivism focused his attention on the study of language, asking about the empirical or verifiable meaning of the propositions. The members of the Vienna Circle thought that Kant had failed there; they had triumphed, that is to say, triumphed in finding a way to place philosophy on the sure path of a science (Ayer, 1959). A proposition is analytic when its validity depends only on the definitions of the symbols that it contains, and synthetic or empirical when it is valid for the facts of the experience. The analytic propositions, as those of logic and mathematics, are irrefutable. The synthetic propositions, with informative content, depend on their empirical verification, on their verification with the facts of the appreciable experience. The denomination of logical empiricism defines the fundamental characteristics of the movement: empiricism because outside of mathematics only the susceptible formulations of observations acquire significance, and logical because logic provides the formal structure that a scientific discourse must have. Thinkers like Carnap or Hempel defended the idea that scientific theories are formal, axiomatic systems with some empirical interpretation. They took mathematics as the model and the only thing that the 
scientific theories of mathematics and logic would distinguish is that the non-logical expressions possess an empirical interpretation (Psillos, 2000). Then the meaning of said expressions would be defined from the meaning of the observed expressions that take place in the act of verification ${ }^{1}$; "statements whose truth or falsity is not in their logical forms or meaning and which are not experimentally testable are considered meaningless" (Maleeh \& Amani, 2013, p. 356).

The verification method of positivism will be questioned by the method of falsifiability of Karl Popper (Popper, 2002). The authentic scientific theories are those determined by decisive proof; a proof in the form of prediction deduced from the theory itself and that could be confirmed by observation, or not. The nonscientific theories are those that accumulate facts that reinforce their own approaches, disregarding other facts that refute them. The overcoming of the empirical evidence to which the theory has been subject allows one to maintain the valid character of the conjectures, until there is new evidence. The epistemological position adopted by Popper was a "conjectural scientific realism" where the hypotheses or theories never get to overcome the status of mere conjectures, which points out "the fallibility of science, but that does not mean skepticism or relativism" (Rivadulla, 2015, p. 53).

The optimistic vision of the first decades of the 20th century has changed a lot since its origins. Popper's falsifiability will be worn down by the works of Willard Quine, Thomas Kuhn, Imre Lakatos and Paul Feyerabend. For Popper, the appearance of a phenomenon that contradicts a theory must mean the rejection of the theory. However, for Lakatos, the elimination of the peripheral elements of a theory-hypotheses deduced from the "hard core"-does not imply the questioning of the research programme: "mere 'falsifications' must no imply rejection" (Lakatos, 1970, p. 99). No empirical difficulty or anomaly is sufficient to end a paradigm or research programme. Observation is determined by theories and these are composed of research postulates that can be plural or variable. As a consequence, the statements of observation can be heterogeneous. From the middle of the 20th century, philosophy of science begins to speak, not only of the fallibility of theories, but of the trust or belief in research programs. The crisis of classical physics will lead to a loss of confidence in logic, which is added

1 "Schlick says: '... a genuine statement must be capable of conclusive verification'; and Waismann says still more clearly: 'If there is no possible way to determine whether a statement is true then that statement has no meaning whatsoever. For the meaning of a statement is the method of its verification."” (as cited in Popper, 2002: 17). 
to the loss of confidence in the verification made possible by the senses because of its theoretical presuppositions (Hanson, 1958). New forms of realism-such as the internal realism of Hilary Putnam-contributed to revive the epistemological debate, which was increased when new neopragmatic tendencies were given way to ideas of Charles Pierce, John Dewey, William James and Pierre Duhem, among others.

For Dewey, the starting point is the indeterminate situations, the antecedent condition of inquiry: "they are disturbed, troubled, ambiguous, confused, full of conflicting tendencies, obscure, etc." (Dewey, 1938: p. 105). Facing these kinds of situations, a plurality of operational processes or methodological strategies are possible. Dewey overcomes, through the concept of experimentation, the division between facts and values; objective facts that the positivist method has to verify-or falsify in the case of Popper's conjectural realism-and values that the human sciences would be capable of understanding - and that positivism would define as "the emotional". For Dewey, "art and science, for example, they are all forms of practice" (Gouinlock, 1990, p. 257). The logic of the inquiry is the same pattern for all human activity, closing the gap between natural sciences and human sciences, since the very logic spreads to all human activities.

The modern conception of the scientific method would have generated privileged vocabularies with a generalized application that is not content with stating "that a given vocabulary works better than another for a given purpose" (Rorty, 1982, p. 193). The recognition of other possible vocabularies can develop linguistic practices that can solve situations of uncertainty without reducing everything to a mathematical vocabulary, for example. For Rorty "the weak textualist thinks, with Dilthey and Gadamer, that there is a great difference between what scientists do and what critics do" (Rorty, 1982, p. 153). However, the only difference is between vocabularies "that let us get what we want" (1982, p. 153), that is, to solve the different types of problems that human beings are facing. For Rorty (2007, p. 83) - as a reader of Berlin and Dewey_ "inquiry need have no higher goal than the solving of problems when they arise".

This introduction of uncertainty into the theories, which are converted into provisional conjectures, take place parallel to the changes in physics. The new physics introduces elements of probability and uncertainty that question the deterministic laws of nature, in particular, the use of the concept of causality and the objectivity of the exterior world. For Heisenberg, the indeterminacy of initial values impeded the predictability of future values, rejecting an operational significance of causality (Heisenberg, 1971). In 
the strong formulation of the law of causality, if we know the present with precision, then we are able to predict the future. Given that the antecedent can never be true, Heisenberg deduced that the conditional statement is false.

The conception of classic observation, as passive reception of the information that comes from the outside, utilizes the metaphor of thinking as a mirror of nature, a mirror that does not disturb said information in the process of observation (Rorty, 1979). But in the microphysical world, the existence of Plank's constant makes that the instrument that utilizes the subject disturbs the object, and, therefore, that one cannot distinguish exactly what is the observing subject and what is the object observed, "it is now profitable to review the fundamental discussion, so important for epistemology, of the difficulty of separating the subjective and the objective aspects of the world" (Heisenberg, 1949, p. 65). Similarity, Bohr considered that the distinction of subject-object, typical of the classic conception, was an idealization that was not upheld in atomic physics, where the terms 'subject', 'object', and 'observation' lost their usual meaning (Bohr, 1949). From philosophical realism, Roger Penrose defends the existence of an objectively real state of a particle, described by its wave function $\psi$, though for John Archibald Wheeler, the wave function that verifies Schrödinger's equation constitutes the central question of quantum mechanics, which remains open (Rivadulla, 2004). From the Copenhagen interpretation-that we cannot make any objective affirmation about the world without putting ourselves in contact with it-Schrödinger deduced that the interference between subject and object is not inevitable, rather that there is no interference because there is no difference between subject and object: "in Schrödinger`s metaphysics, subject and object are not two pre-given entities facing each other, which had to wait for quantum mechanics in order to merge. They are one from the outset" (Bitbol, 1996, p. 24). There is no difference between the existent world and the perceived world. The world is given only one time. The original image and the reflected image are identical. The world given in space and time is only our representation. Consequently, for Schrödinger, subject and object are only one thing. Furthermore, "we cannot say that the barrier that separates them has been broken as a consequence of the recent experience of physics because that barrier does not exist" (Castellá, 2016, p. 289-290).

For Dewey, "experience does not passively reproduce or copy its objects” (Shook, 2004, p. 739). Dewey's philosophy of science includes a sophisticated and somewhat peculiar form of contextualism, or "situationism" 
(Brown, 2012, p. 268). Dewey's pragmatic conception coincides with this point by overcoming the limitations of the dualistic epistemological positions - the theory of representation-getting past the use of the traditional terms subject and object. For that, the distinctions between objectivity and subjectivity are substituted by a new category, the situation. The real experience is so from a situation understood as a unit formed by the organism and the surroundings: "for we never experience nor form judgments about objects and events in isolation, but only in connection with a contextual whole. This latter is what is called a 'situation'" (Dewey, 1938, p. 66).

The great debate surrounding the Copenhagen interpretation in quantum physics (van Fraassen, 1991) revolves around the positivist presuppositions of Mach, the logical positivist presuppositions and the pragmatist presuppositions (Stapp, 1972; Maleeh \& Amani, 2013). For Maleeh \& Amani (2013, p. 365), "if one were supposed to classify the Copenhagen interpretation, the closest approximation would be to view it as a pragmatist philosophy". Schrödinger shared with both Heisenberg and Einstein the influence of Mach's thought that permeated the intellectual atmosphere of the time, but it is in Schrödinger where one most deeply perceives said influence, not only for the positivist ideas regarding the progress of sciencefrom which he would progressively distance himself-rather for the monist ontology that always remained at the base of his thinking. The thinking of Bohr approaches instrumentalism by defining scientific theories as instruments that allow us to construct more and more organized descriptions of phenomena ${ }^{2}$; and pragmatism, with "his semantic conception of the complementarity of the position and the moment, that is, his thesis that one cannot say that a particle has at the same time an exact position and moment" (Castellá, 2016, p. 136).

2 "Bohr holds a non-realist view when it comes to the applicability of a theory of pure mathematics to the real physical world, seeing the value of such a theory as primarily instrumental. Such a theory would be a useful tool for organizing our observations and making predictions under well-defined conditions. Bohr is highly sceptical of the view that the physical world can be uniquely described by some theory of pure mathematics [...] The mathematical formalism of quantum mechanics does not give us any 'pictorial' representation of the world" (Maleeh \& Amani, 2013, p. 360-361). 


\section{John Dewey's conception of the scientific method}

\subsection{The pattern of inquiry}

The appearance of incertitude- "inquiry grows out of an earlier state of settled adjustment, which, because of disturbance, is indeterminate or problematic" (Dewey, 1938, p. 34)—entails a series of processes mediated by symbols that seek to transform the initial situation into something balanced and definite. The inquiry is situated, then, in an intermediate space between uncertainty and certainty, that space of transition and transformation in which the use of symbolic means-ideas-are capable of resolving the given situation. If the Kantian transcendental reflection spoke about the transcendental conditions of the possibility of experience, Dewey spoke about problematic conditions. The conditions are problems and the problems take the form of questioning. For Dewey, to think is to create a problem since, "...from the standpoint of both science and common sense, it would seem more correct to say that a question (in the sense of a questionable and questioned subject-matter) is the object of thought" (1938, p. 169). The condition for the development of knowledge, through ideas that act as operational hypotheses that try to dissolve the problems, is the appearance of questioning, given that, “...inquiry and questioning, up to a certain point, are synonymous terms. We inquire when we question; and we inquire when we seek for whatever will provide an answer to a question asked" (1938, p. 105).

Therefore, the conditions that unfold symbolic-operational processesthat are manifest under the form of concepts, hypotheses, or scientific theories-are problems, and the problems are real, objective situations in the classic sense of the term. The operationalism of Dewey understands that ideas are the keys that, in the form of hypotheses, attempt to open the lock of the "problematic situations" (1938, p. 107), that is, of situational problematic facts. The production of ideas is the production of new attempts of action that can crystallize into logic, hypotheses, and postulates different from those that are available.

The logic of Dewey's inquiry is not closed to a specific area of knowledge, rather to the entire area of vital human activity. For Dewey "there are no primary or intrinsic qualities" (Valor, 2011, p. 218). The difference that distinguishes daily behavior and the behavior that a physicist or a mathematician can perform is reduced to a difference of objective, both are practices and "the working scientist is a practitioner" (1938, p. 161). In some cases, the objectives will determine a more complex series of operational ideasdiverse ways of measuring objects, calculations, etc.-while in others, the 
objectives will generate simpler ideas - as might be the problems in the daily life of a home. For Dewey, "art, science and practical activity have significant subject matter and procedures in common" (Gouinlock, 1990, p. 257); they are forms of practice with different aims but under a common pattern.

The structure of the inquiry establishes a universal pattern, a logical unity, that has, nonetheless, different procedures because, “... the different objectives of common sense and of scientific inquiry demand different subject-matters and that this difference in subject-matters is not incompatible with the existence of a common pattern in both types" (Dewey, 1938, p. 116). All inquiry emerges from a problem (pattern or universal structure), but the problems are different (singularity of problem), setting out different responses or necessities (operational hypotheses). For Dewey, there is a common pattern or structure of inquiry that unifies the problems of the natural sciences and the problems of the social sciences and humanities. That is, "there is no ontological difference - between man and nature- that dictates a methodological difference" (Rorty, 1982, p. 199).

The inquiry is a collection of experimental operations that come defined by the conditions of uncertainty. The problems interrupt the habitual flow of a settle and unified situation, that is, that fluid state that comes characterized by the sensation of control, well-being, and balance. The conditions that give rise to an inquiry are doubts, situations of doubt, where the concepts that distinguish and connect elements, articulated in theories or theoretical hypotheses, are unable to resolve the problems. The theories and tools, capable of resolving the problems set out in past situations of uncertainty, demonstrate their functional inability by not fulfilling their new objectives, maintaining the situation of uncertainty. The belief in the utility of theory to resolve problems fades. Dewey will not speak about belief, like Peirce, rather of warranted assertibility: "If inquiry begins in doubt, it terminates in the institution of conditions which remove need for doubt. The latter state of affairs may be designated by the words belief and knowledge. For reasons that I shall state later I prefer the words warranted assertibility" (Dewey, 1938, p. 7).

To remove the doubt and reach warranted assertibility is the aim of the researcher. The concept of warranted assertibility seeks to point out the imperfect character of knowledge or of belief, placing emphasis on the progressive character of the scientific activity. Knowledge is a momentary image of a process in constant motion without end, that is, without irrevocable, absolute conclusions. All inquiry can later put in doubt parts or elements of a settled or established belief since, "in scientific inquiry, the 
criterion of what is taken to be settled, or to be knowledge, is being so settled that it is available as a resource in further inquiry; not being settled in such a way as not to be subject to revision in further inquiry" (ibid.). In Dewey, the pattern of inquiry is a game of elements, of keys and locks, of solutions and problems, without a final opening or master key. The openings generate new closures, the solutions new problems. There is no final solution or definitive goal of the inquiry, which forces an unlimited and creative production of ideas, hypotheses, concepts, or postulates.

\subsection{Freedom of postulation}

Dewey's approaches break with the a priori vision of logic. Logic is situated within the inquiry, not above or external to it. The logic of Dewey is immanent, that is, it emerges from the problems that the researcher sets out. Logic depends on the problems that are set out given an indeterminate situation. The uncertain situation, as a fissure of the determinate situation, is the origin of the processes of the definition of problems and the choice of strategies. Logic is one of these choices. This means that logic depends on the uncertainty unleashing from the inquiry as a whole, and the uncertainty is not something controllable once and for all and for always; the uncertainty is an occurrence that can create the situation where the traditional forms of logic do not demonstrate their functional effectiveness, requiring new forms of logic that guarantee the closing of the crack opened by the uncertainty. The forms of logic emerge within the investigational operation. Logic ceases to be external to the inquiry: logic ceases to be metaphysical, transcendent, or transcendental.

There is no logical world external to the processes of the definition of problems, unleashed by a situation of incertitude or disorganization that breaks with the stability of a determinate or integrated situation. If the inquiry wants to reach valid conclusions, "it must itself satisfy logical requirements. It is an easy inference from this fact to the idea that the logical requirements are imposed upon methods of inquiry from without" (1938, p. $5)$. Nonetheless, the logical requirements, external to the inquiry, as absolute principles, have demonstrated their inability to resolve scientific problems, limiting the progress of science. Meanwhile, the logical forms and criteria development in an inquiry underway have demonstrated their functionality: "as the methods of the sciences improve corresponding changes take place in logic" (1938, p. 14). Logic external to the inquiry breaks with the real process of the inquiry itself and supposes a hindrance to the attainment of scientific success. Dewey's interest is to favor the development of science, 
a development that metaphysical epistemology can hinder, as the history of science shows us: "when hypotheses have been taken to be finally true and hence unquestionable, they have obstructed inquiry and kept science committed to doctrines that later turned out to be invalid" (1938, p. 142).

A relevant example of these approaches can be found in the history of physics in the XX century. Einstein, a defender of the realist model of classical physics, of causal relationships and of the distinction between subject and object, rejected probabilism and the questioning of the principle of identity. Pragmatist philosophy would favor the development of the new science, a completely different paradigm that saw subject and object as an unbreakable unity and accepted chance. When Bohr introduced the notion of complementarity in 1927, he achieved a heuristic function to interpret the two kinds of experiments. The wavy and corpuscular nature of light and material generated a problem of logical coherence among physicists. The notion of complementarity was a useful resource to maintain some models of classical visualization without necessity of recurring to real philosophical positions. However, that notion "did not lead to discovering new theoretical laws that permitted one to make precise and contrastable predictions and it was possibly for that reason that Einstein said that he did not understand the meaning of complementarity" (Castellá, 2016, p. 105)

If logic is a question within the inquiry, that also affects the statute of mathematics. In the 19th century, although the consistency of non-Euclidean geometry was founded on Euclidean geometry, the loss of consistency of the Euclidean geometry led Kronecker and Frege to base mathematics on arithmetic, an attempt that was questioned by Helmholtz when he made the concept of number dependent on experience (Kline, 1980). The attempts of foundation would reach more pragmatic positions centered in the freedom of postulation and the utility of axioms. The absolute axioms are transformed into useful postulates to resolve situations of incertitude. Knowledge, by abandoning the attempts at complete grounds, allows for

${ }^{3}$ The debate and the epistemological consequences of these approaches that question philosophical realism must be pointed out. Einstein himself, adversary of the Copenhagen interpretation, resisted, being considered by Heisenberg a "dogmatic" realist. Popper's conjectural-realism resisted instrumentalist tendencies: "The central issue here is realism (Popper, 2000, p. 2) [...] But my historical conjecture is that by that time, the subjectivist dogma was too deeply entrenched within the ruling interpretation of quantum mechanics, the so-called Copenhagen interpretation; and even Heisenberg's occasional talk of objective possibilities (by which he meant something very similar to my propensities) did not remove the subject - the observer - from the Copenhagen interpretation; nor was it intended to do so" (2000, p. 5). 
the entrance of contingency, making possible the appearance of new postulates that can demonstrate their usefulness as means to reach warranted assertiveness. The freedom of postulation, in logic and in mathematics, appears as valid criteria for all inquiry, always when those postulates demonstrate their usefulness in the solution of problems; "the greatest freedom is permitted, or rather encouraged, in laying down postulates-a freedom subject only to the condition that they be rigorously fruitful of implied consequences" (Dewey, 1938, 10).

\section{Analysis: philosophical consequences}

An uncertain situation manifests as a limitation in our habitual behavior. This limitation is the real condition for the development of a whole series of practical processes that consist in determining the nature of the problem in question- "the facts of the case constitute the terms of the problem" (Dewey, 1938, p. 109)—and producing hypotheses that serve as tools for resolving it. There is no a priori method or pre-established plan since the conditions from which we proceed to resolve the uncertainty are variable and singular. The practices directed at the resolution of problems are determined by indefinite and temporal conditions that express limitation and surprise. These conditions are changing and the processes of resolution of problems depend on how one has defined the indeterminate situation. The pragmatism of Dewey values the role of human creativity in scientific process. To create ideas is to make practical hypotheses that are dependent variables of the conditions imposed by the problem. Its effectiveness will manifest if they achieve what they promise, that is to say, the effect of the reduction of disorder. This instrumentalist vision defines the meaning of a tool by its effects, "any map in any system is 'true' (that is, valid) if its operational use produces the consequences that are intended to be served by the map" (1938, p. 403).

The situations of uncertainty or indeterminate situations are essentially situations of change, and this implies that they are not necessarily equal; the ways of proceeding depend on variable conditions and innovation is a fundamental element. There exists a creative element that gives rise to the appearance of procedural novelties, which does not mean that the heritage of knowledge accumulated over time and the stereotyped solutions to problematic situations more or less fixed or recurrent cannot be useful (Faerna, 1996). It is a matter of balancing the normal knowledge-the heritage 
of accumulated knowledge-with the innovative element-new discursive tools that are necessary to create when there are situations of incertitude. These ideas connect with Thomas Kuhn's philosophy of the science. Crisis situations put in doubt the theoretical tools utilized to resolve problems. The traditional tools become a problem:

So long as the tools a paradigm supplies continue to prove capable of solving the problems it defines, science moves fastest and penetrates most deeply through confident employment if those tools. The reason is clear. As in manufacturing, so in science-retooling; it is an extravagance to be reserved for the occasion that demands it. The significance of crises is the indication they provide that an occasion for retooling has arrived (Kuhn, 1996, p. 76).

The logic of inquiry, for all disciplines, consists in producing operational hypotheses, key-ideas that will try to open the locks. The hypotheses are corroborated when they generate effects of order in the situations-something distinct from the method of verification or falsification-achieving, temporarily, a more ordered or definite situations: "a unified whole" (Dewey, 1938, p. 105). The methodological strategies prove their capacity to reduce the uncertain situations; new practices need to be tested in order to achieve disorder reduction if disorder persists. How one proceeds facing a problem is therefore determined a posteriori; there is no a priori method, and the experimentation will determine the utility of a strategy, which does not mean that there is no repertoire of operational procedures for known and specific problems.

These approaches will allow for the development of the neopragmatist postulates of Rorty $(1982 ; 1989 ; 1991 ; 2007)$ and they are adaptable to some of the postulates of the constructive empiricism of van Fraassen (1991, p. 16) since, as he affirms in an instrumentalist way, "it is not necessary for a model to have all its elements correspond to elements of reality. What is needed instead is that the model should fit the phenomena it was introduced to model". However, while Rorty rejects the representation theory, "van Fraassen avoids the problem by talking about correspondence between the theoretical model and the data model" (Rivadulla, 2015, p. 42-43). The process of the inquiry, begun with the aim of recuperating the balance of the situation, does not reach final, finished, or definitive states; once the state of balance is reached, it can break, giving rise to new tensions since, "as special problems are resolved, new ones tend to emerge. There is no such thing as a final settlement, because every settlement introduces the conditions of some degree of a new unsettling" (Dewey, 1938, 35). The activities carried out to satisfy necessities are practically unlimited since they 
change "the environment and new needs arise which demand still further change in the activities of the organism by which they are satisfied; and so on in a potentially endless chain" $(1938,28)$.

Dewey's logic of inquiry addresses the definition of the universal logic of nature. This logic gives rise to a methodological pluralism, a multiplicity of methodological strategies that attempt to suture the open gap by the situations of incertitude. The production of new ideas takes place when the strategies from the past cease to work, when they cease to generate ordered situations, continuing the disorder and uncertainty. The novelty of the problems forces the formulation of new methods, hypotheses, and practical postulates in order to achieve situations that are more ordered or determinate. Far from relativism - "I would hope that we are now in a position to see the charges of 'relativism' and 'irrationalism' once leveled against Dewey as merely the mindless defensive reflexes of the philosophical tradition which he attacked" (Rorty 1979, p. 13) - the pragmatism of Dewey supposes a framework of re-organization of scientific and epistemological problems with less contradictions than in previous theories.

\section{Conclusion}

Nowadays, several pairs of opposing concepts lead to unpleasant or indeterminate situations. The urban is opposed to biodiversity, transport to health, food to animal sentience and welfare. A variety of practices try to transform these situations of uncertainty generated by these oppositions into determined and integrated situations. As a result, we would be able to have food without pain, sustainable transport or habitable cities. The notion of complementarity does not force us to decide between health and city, or reason and emotion. These concepts can be part of an integrated and coherent whole.

From the point of view of the philosophy of science, the principle of complementarity provided by the Copenhagen interpretation of quantum physics has an application in the human and social sciences. New epistemological approaches are needed that apply to different areas of research. One example is the economic science, where the pursuit of sustainable development goals must be valued in the same way as economic growth - perhaps we should use the concept of economic development. If we follow Dewey's theory of inquiry, we discover that logic is not a fixed research budget, but that it is developed within the inquiry. A certain logic will have meaning if 
it is capable of solving the problems that arise in the form of situations of uncertainty. Just as the notion of complementarity made it possible to interpret certain experimental physical situations, we hope that this notion can be a useful logical principle for solving the current problems posed by the social sciences and humanities without generating privileged vocabularies or methods. In the face of the classic opposition between subject and object - which in the economic sciences is manifested by the confrontation between financial and non-financial aspects- a complementary vision of our social being would make it possible to understand that the conservation of biodiversity is just as necessary as the purely traditional economic aspects.

The global ecological crisis and the quest for sustainable development force us to redefine our theoretical foundations if we want to overcome this situation of discomfort and uncertainty in order to reach a more integrated, determined and fluid situation. The need to preserve the conditions of existence of the planet leads us to develop new complementary logics where the logic of disjunction is replaced by a logic of connection, relationship and interdependence. This implies abandoning the model of the subject - business separated from society by an ontological abyss - and the model of the object - nature as a resource to be used without limit whose destruction cannot affect us- for a unified model based on a situational ethics. The challenge is to ensure that economy and sustainability goals are not antagonistic but complementary aspects, leading to a more fluid and integrated situation where irritation, discomfort and unpleasantness are reduced by methodological problem-solving strategies.

\section{References}

Ayer, A. J. (Ed.) Logical positivism, New York, Simon and Schuster, 1959. Bächtold, M. "Interpreting quantum mechanics according to a pragmatist approach", Foundations of Physics, 38, 843 (2008).

Bitbol, M. Schrödinger's philosophy of quantum mechanics, The Netherlands, Kluwer Academic Publishers, 1996.

Blum, L. A. Friendship, Altruism and Morality. London, Routledge and Kegan Paul, 1980.

Bohr, N. "Discussion with Einstein on Epistemological Problems in Atomic Physics", en P.A. Schilpp (ed.), Albert Einstein: Philosopher-Scientist, The Library of Living Philosophers, Vol. VII, Evanston, Illinois, 1949, pp. 201-241. 
Bohr, N. Atomic Physics and Human Knowledge. New York, John Wiley, 1958.

Bohr, N. Essays 1958-1962 on atomic physics and human knowledge. New York, Interscience Publishers, 1963.

Brown, M. J. "John Dewey's logic of science", HOPOS: The Journal of the International Society for the History of Philosophy of Science, 2(2) (2012), 258-306.

Burtt, E. A. The metaphysical foundations of modern physical science: A historical and critical essay. New York, Dover publications, 2003.

Castellà, J. Origen e implicaciones filosóficas de las medidas cuánticas sin interacción. La filosofía de la física de M. Renninger, Tesis Doctoral, Universidad Autónoma de Madrid, 2016.

Dewey, J. Logic. The Theory of Inquiry. New York, Henry Holt \& Co, 1938.

Faerna, A. M. Introducción a la teoría pragmatista del conocimiento, Madrid, Siglo XXI, 1996.

Gouinlock, J. "What is the legacy of instrumentalism? Rorty's interpretation of Dewey", Journal of the History of Philosophy, 28(2) (1990), 251-269.

Hanson, N. R. Patterns of Discovery: An Inquiry into the Conceptual Foundations of Science. Cambridge, Cambridge University Press, 1958.

Healey, R. "Quantum Theory: Realism or Pragmatism?", Análisis. Revista de investigación filosófica, 5(1) (2018), 111-138.

Heisenberg, W. The physical principles of the quantum theory, New York, Dover Publications, 1949.

Heisenberg, W. Physics and Philosophy: The Revolution in Modern Science, London, Allen and Unwin, (1959) 1971.

Kline, M. Mathematics: The loss of certainty, New York, Oxford University Press, 1980.

Kuhn, T. S. The structure of scientific revolutions. Chicago, University of Chicago Press, (1962) 1996.

Lakatos, I. "History of Science and its Rational Reconstructions", En Buck R.C., Cohen R.S. (eds.) PSA 1970. Boston Studies in the Philosophy of Science, 8, Springer, Dordrecht, 1971, pp. 99-136.

Maleeh \& P. Amani, R. "Pragmatism, Bohr, and the Copenhagen interpretation of quantum mechanics", International Studies in the Philosophy of Science, 27(4) (2013), 349-363.

Marion Young, I. "Impartiality and the civic republic". In Feminism as critique: On the politics of gender. Cambridge, Polity Press in Association with Blackwell Publishers, 1987. 
Maxwell, N. "A critique of Popper's views on scientific method”, Philosophy of Science, 39(2) (1972), 131-152.

Naess, A. (1985). "The world of concrete contents". Inquiry, 28(1-4) (1985), 417-428.

Nolan, L. (Ed.) Primary and secondary qualities: The historical and ongoing debate, Oxford UK, Oxford University Press, 2011.

Popper, K. The logic of scientific discovery, London and New York, Routledge, (1959) 2002.

Popper, K. Quantum Theory and the Schism in Physics: from the Postscript to the Logic of Scientific Discovery, London and New York, Routledge, (1982) 2000.

Psillos, S, "Rudolf Carnap's Theoretical Concepts in Science", Studies in History and Philosophy of Science, 31(1) (2000), 151-172.

Puleo, A. H. "Perspectivas ecofeministas de la ciencia y el conocimiento La crítica al sesgo andro-antropocéntrico", Daimon Revista Internacional De Filosofia, (2017), 41-54.

Rivadulla, A. "La filosofía de la ciencia hoy. Problemas y posiciones", en J. M. Navarro Cordón (ed.), Perspectivas del pensamiento contemporáneo 2, Madrid, 2004, pp. 109-163.

Rivadulla, A. Meta, método y mito en ciencia, Madrid, Editorial Trotta, 2015.

Rorty, R. Philosophy and the Mirror of Nature, New Jersey, Princeton University Press, 1979.

Rorty, R. Consequences of pragmatism: Essays, 1972-1980, Minneapolis MN, University of Minnesota Press, 1982.

Rorty, R. Contingency, irony, and solidarity, Cambridge, Cambridge University Press, 1989.

Rorty, R. Essays on Heidegger and others: philosophical papers (Vol. 2), Cambridge, Cambridge University Press, 1991.

Rorty, R. Philosophy as Cultural Politics: philosophical Papers (Vol. 4), Cambridge, Cambridge University Press, 2007.

Shook, J. R. "Dewey's Empirical Naturalism and Pragmatic Metaphysics." Transactions of the Charles S. Peirce Society 40(4) 2004, 731-742.

Speranza, A. Ecología profunda y autorrealización, Buenos Aires, Editorial Biblos, 2006.

Stapp, H. P. “The Copenhagen Interpretation”, American Journal of Physics, 40(8) 1972, 1098-1116.

Tafalla, M. "La apreciación estética de los animales: consideraciones estéticas y éticas", Revista de bioética y derecho, 28 (2013), 72-90.

Valor, J. A. "Utilidad y objetividad en la investigación científica", Revista de Filosofía, 31(2) (2006), 173-188. 
Valor, J. A. "Una crítica pragmatista a la filosofía moderna, la realidad líquida", Revista de discusiones filosóficas, 12(19) (2011), 199-221.

van Fraassen, B. C. Quantum mechanics: An empiricist view, Oxford, Oxford University Press, 1991.

Velasco, A. "Ética del cuidado para la superación del androcentrismo: hacia una ética y una política ecofeministas”, CTS: Revista iberoamericana de ciencia, tecnología y sociedad, 11(31) (2016), 195-216. 